\title{
Population analysis of the GLB1 gene in South Brazil
}

\author{
Cléia Baiotto ${ }^{1,3 \#}$, Fernanda Sperb ${ }^{1,2 \#}$, Ursula Matte $^{2}$, Cláudia Dornelles da Silva $^{3}$, Renata Sano ${ }^{3}$, \\ Janice Carneiro Coelho ${ }^{3}$ and Roberto Giugliani ${ }^{1,2,3}$ \\ ${ }^{1}$ Programa de Pós-Graduação em Genética e Biologia Molecular, \\ Universidade Federal do Rio Grande do Sul, Porto Alegre, RS, Brasil. \\ ${ }^{2}$ Centro de Terapia Gênica/Centro de Pesquisa Experimental, Hospital de Clínicas de Porto Alegre, \\ Porto Alegre, RS, Brasil. \\ ${ }^{3}$ Serviço de Genética Médica, Hospital de Clínicas de Porto Alegre, Porto Alegre, RS, Brasil.
}

\begin{abstract}
Infantile GM1 gangliosidosis is caused by the absence or reduction of lysosomal beta-galactosidase activity. Studies conducted in Brazil have indicated that it is one of the most frequent lysosomal storage disorders in the southern part of the country. To assess the incidence of this disorder, 390 blood donors were tested for the presence of two common mutations (1622-1627insG and R59H) in the GLB1 gene. Another group, consisting of $26 \mathrm{GM} 1$ patients, and the blood donors were tested for the presence of two polymorphisms (R521C and S532G), in an attempt to elucidate whether there is a founder effect. The frequencies of the R59H and 1622-1627ins mutations among the GM1 patients studied were $19.2 \%$ and $38.5 \%$, respectively. The frequency of polymorphism S532G was $16.7 \%$, whereas R521C was not found in the patients. The overall frequency of either R59H or 1622-1627insG was $57.7 \%$ of the disease-causing alleles. This epidemiological study suggested a carrier frequency of 1:58. Seven different haplotypes were found. The 1622-1627insG mutation was not found to be linked to any polymorphism, whereas linkage disequilibrium was found for haplotype $2(\mathrm{R} 59 \mathrm{H}, \mathrm{S} 532 \mathrm{G})(\mathrm{p}<0.001)$. These data confirm the high incidence of $\mathrm{GM} 1$ gangliosidosis and the high frequency of two common mutations in southern Brazil.
\end{abstract}

Key words: GM1 gangliosidosis, beta-galactosidase, GLB1 gene, founder effect, linkage disequilibrium.

Received: April 28, 2010; Accepted: October 29, 2010.

GM1 gangliosidosis and mucopolisaccharidosis IV$\mathrm{B}$ (Morquio B) are lysosomal storage disorders caused by a $\beta$-galactosidase (GLB1; EC 3.2.1.23) deficiency. This deficiency occurs due to mutations in the GLB1 gene, but the differences that lead either to GM1 gangliosidosis or to Morquio B are not known so far. GLB1 is located on chromosome 3 at 3p21.33 (Takano and Yamanouchi, 1993) and is composed of $62.5 \mathrm{~kb}$ divided into 16 exons (Morreau et al., 1989). Hypotheses have been raised proposing that more than 100 different mutations could be responsible for the Morquio or GM1 gangliosidosis phenotypes (Callahan, 1999; Brunetti-Pierri and Scaglia, 2008). However, patients with intermediate phenotypes have also been described (Giugliani et al., 1987; Mayer et al., 2009).

The incidence of type $1 \mathrm{GM} 1$ gangliosidosis is considered to be between 1:100,000 and 1:200,000 live births (Sinigerska et al., 2006). However, higher frequencies have been described for specific regions, such as Malta $(1: 3,700)$

Send correspondence to Ursula Mattes. Rua Ramiro Barcelos 2.350, Bairro Santa Cecília, 90035-903 Porto Alegre, RS, Brazil. E-mail: umatte@ hcpa.ufrgs.br.

\# These authors contributed equally to this work.
(Lenicker et al., 1997). The incidence in Brazil has been estimated at 1:17,000 live births, and the carrier frequency was found to be 1:67 (Severini et al., 1999). Mutation analysis performed in 19 Brazilian patients detected the presence of mutations 1622-1627insG (Silva et al., 1999) and/or R59H (Morrone et al., 1997) in about $60 \%$ of the alleles. These results stand out when compared to mutation frequencies found by other groups in different parts of the world.

Here, we report a screen to detect and confirm the incidence of type 1 GM1 gangliosidosis in southern Brazil by analyzing 390 anonymous blood donor samples for the presence of the two common mutations. In addition, these control samples and a group of $26 \mathrm{GM} 1$ patients were tested for the presence of two polymorphisms located within the GLB1 gene, in an attempt to elucidate whether there is a founder effect, which could explain the high frequency of this disorder in the studied region.

Mutation analysis was performed on samples from 26 unrelated patients with GM1 gangliosidosis and their relatives (whenever possible) to determine the ligation phase of the alleles. 
Patients were diagnosed at the Laboratory of Inborn Errors of Metabolism of the Hospital de Clínicas de Porto Alegre (LREIM/HCPA), Brazil. The diagnosis was confirmed by low levels of $\beta$-galactosidase enzyme activity in leukocytes. Anonymous control samples were collected from blood donors of the HCPA Blood Bank, for a total of 390 samples.

Genomic DNA was extracted from peripheral blood leukocytes, using the salting-out procedure (Miller et al., 1988). Molecular analysis was performed using PCR for exons 2 and 15, in order to detect the R59H, 16221627insG, R521C and S532G mutations. Primers and conditions were as described by Silva et al. (1999). The PCR fragments of exon 2 were digested with NlaIII (New England Biolabs) and visualized on a $3 \%$ agarose gel, to assess for the presence of the R59H mutation. Gels for SSCP (single-strand conformation polymorphism) analysis of exon 15 contained 25\% MDE (Mutation Detection Enhancement - FMC) and 5\% glycerol, and were run for $14-15 \mathrm{~h}$ at $250 \mathrm{~V} / 4 \mathrm{~W}$ at room temperature. The gels were silverstained as described by Orita et al. (1989). Alterations were identified by comparison with known sequenced samples. Nucleotide sequences were aligned using the Alignment Explorer/ClustalW Molecular Evolutionary Genetics Analysis (MEGA) software version 4.0 (Tamura et al., 2007). Linkage disequilibrium was calculated using the DNA Sequence Polymorphism 5 (DNASP) program (Rozas and Rozas, 2000) and the haplotype construction.

We investigated 26 patients with GM1 gangliosidosis for mutations R59H and 1622-1627 and for polymorphisms R521C and S532G. Twenty-two patients had one or both mutations. The frequencies of R59H and 1622-1627insG were $19.2 \%$ and $38.5 \%$, respectively (Table 1 ). The frequency of the S532G polymorphism was $15.4 \%$, while that of the R521C polymorphism was 0 (zero); the latter polymorphism was however present in one of the parents of four patients. Four patients presented none of the aforementioned mutations.

The frequencies of these two disease-causing mutations and of the two polymorphisms in 390 control subjects
Table 1 - Allele frequencies in patients and controls.

\begin{tabular}{lcccc}
\hline Alleles & \multicolumn{2}{c}{ Patients } & \multicolumn{2}{c}{ Controls } \\
\hline R59H & $10 / 52=$ & 0.192 & $1 / 780=$ & 0.001 \\
1622-1627insG & $20 / 52=$ & 0.385 & $3 / 780=$ & 0.004 \\
S532G & $8 / 52=$ & 0.154 & $58 / 780=$ & 0.074 \\
R521C & $0 / 52=$ & 0.0 & $21 / 780=$ & 0.027 \\
\hline
\end{tabular}

are also shown in Table 1. The R59H mutation was in heterozygosis in one subject, and the 1622-1627insG was in heterozygosis in another three. The estimated overall frequency of these two mutations is $0.5 \%$ in the normal population of Porto Alegre. The higher frequency of polymorphism S532G in patients (0.154) than in controls $(0.074)$ was marginally significant ( $p=0.046$, Fisher's Exact Test), whereas R521C showed no difference between the two groups.

Because R59H and 1622-1627insG correspond to $57.7 \%$ of the disease-causing alleles, it was possible to estimate the frequency of mutant alleles in the population of Porto Alegre at 0.0007509 and the carrier proportion at 1:58. These figures would lead to a disease incidence of 1:13,317 live births.

Polymorphisms R521C and S532G were used in haplotype analysis to identify a founder effect in the Brazilian population. Seven different haplotypes were found. Table 2 shows the haplotype frequencies in patients and in controls. In about $10 \%$ of the patients and $2 \%$ of the controls it was not possible to determine the haplotypes.

In the patient group, haplotype 2 was the most frequent $(36.5 \%)$, but close to haplotype 1 (34.6\%). Haplotypes 3 and 7 were found only in the control group, in which haplotype 1 was the most frequent $(89.1 \%)$. The $1622-$ 1627 insG mutation was not found to be in linkage disequilibrium with any polymorphism, whereas R59H was found to be in linkage disequilibrium with S532G (haplotype 5) in the patient group $(\mathrm{p}<0.001)$.

Severini et al. (1999) reviewed 63 GM1 type I cases diagnosed at the LREIM/HCPA and found that $68 \%$ were

Table 2 - Haplotype frequencies (as to the presence of R59H and 1622-1627insG mutations and R521C and S532G polymorphisms) in patients and controls.

\begin{tabular}{llll}
\hline Haplotype & $\mathrm{R} 59 \mathrm{H} ; 1622-1627 \mathrm{insG} ; \mathrm{R} 521 \mathrm{C} ; \mathrm{S} 532 \mathrm{G}^{*}$ & Patients $(\mathrm{n}=52)$ & Controls $(\mathrm{n}=780)$ \\
\hline 1 & $1-1-1-1$ & 0.346 & 0.891 \\
2 & $1-2-1-1$ & 0.365 & 0.003 \\
3 & $1-2-1-2$ & 0.0 & 0.001 \\
4 & $2-1-1-1$ & 0.058 & 0,001 \\
5 & $2-1-1-2$ & 0.097 & 0.0 \\
6 & $1-1-1-2$ & 0.019 & 0.068 \\
7 & $1-1-2-1$ & 0.0 & 0.019 \\
8 & $\mathrm{ND}$ & 0.115 & 0.016 \\
\hline
\end{tabular}

* 1 = wild-type allele; $2=$ mutant allele; $\mathrm{ND}=$ not determined. 
from the State of Rio Grande do Sul. The epidemiological study suggested a carrier frequency of 1:67. This observation was confirmed by the molecular analysis of the 390 control subjects of the present work. The presence of four heterozygous individuals led to the determination of a carrier frequency of 1:58 in Porto Alegre. This number is similar to the phenylketonuria carrier frequency in the same area (1:56) (Santana da Silva et al., 2003) and similar to that of Gaucher and Tay-Sachs disease carriers among Ashkenazi Jews (Risch et al., 2003).

Using these figures, we were able to estimate the incidence of GM1 type 1 in Porto Alegre at 1:13,317 live births, slightly higher than that of 1:17,000 live births reported by Severini et al. (1999). These frequencies are extremely high when compared to those found in other studies, reported to be 1:100,000-1:200,000 (Beattie and Harvey, 1992; Sinigerska et al, 2006) and 1:320,000 (Meikle et al., 1999). The small proportion of consanguineous couples in our sample (a single case out of 26) is also consistent with the high incidence of this disorder in Brazil, especially considering that $27 \%$ of the patients were found to be homozygous for one of the two analyzed mutations.

The two mutations (R59H and 1622-1627insG) were detected in $57.7 \%$ of the alleles. This number is quite high for a heterogeneous genetic disorder like GM1 gangliosidosis, for which about 100 mutations were described (Brunetti-Pierri and Scaglia, 2008). The R59H mutation was first described by Morrone et al. (1997) in an Italian patient. Silva et al. (1999) found this mutation in $23.8 \%$ of the alleles of 20 Brazilian patients. These patients presented cardiac involvement similar to that described by Morrone et al. (2000). Santamaria et al. (2006) and Sinigerska et al. (2006) suggested that the R59H mutation is of Gypsy origin and that the presence of this mutation in South America is a reflection of their diaspora.

The 1622-1627insG mutation has only been reported in Brazilian patients so far, except for one patient from Uruguay described by Santamaria et al. (2007a). Silva et al. (1999) found a frequency of $42.8 \%$ for this mutation. Taken together, these two mutations showed a frequency of $62.5 \%$ in the patients studied by Silva et al. (1999), which is similar to the one found in the present work (57.7\%).

Polymorphism S532G was significantly more frequent in patients than in controls. It is not clear if this alteration has an effect on protein activity, because expression data showed contradictory results, with values ranging from $41 \%$ (Hilson et al., 1995) to 86\% (Zhang et al., 2000) of normal enzyme activity.

The R521C polymorphism was found only in controls and in four parents of patients, but not in any of our patients. This polymorphism was first described by Silva et al. (1999) and was present in 10\% of patients' alleles. However, in that sample, this polymorphism was found in patients bearing other mutations than the ones studied in this work. Caciotti et al. (2005) described a patient who was ho- mozygous for R521C and assumed that it was likely to be the disease-causing mutation. In the work of Santamaria et al. (2007b), the R521C polymorphism resulted in $33.2 \%$ enzyme activity. This observation could explain the apparent paradox of $4 \%$ of the general population of Porto Alegre carrying the R521C mutation, since it could have a low penetrance rate (Santamaria et al., 2007b).

The lower frequency of haplotypes 6 (S532G only) and 4 (R59H only) in relation to haplotype 5 (R59H and S532G) suggests that each of these DNA changes took place independently and that recombination events were responsible for their grouping in haplotype 5. Moreover, the statistical analysis indicated the occurrence of at least one recombination event.

It was not possible to precisely define the existence of a founder effect, despite the high frequency of 1622 167 insG among patients, because this mutation was not linked to any of the polymorphisms studied. As this mutation is an insertion of one $\mathrm{G}$ into a string of six Gs, multiple origins cannot be ruled out. However, if this were the case, this mutation would be expected to have also been found in other populations. The fact that this mutation was never reported in any other region is strongly suggestive of a founder effect in the southern part of Brazil and in Uruguay. Supporting this hypothesis, there is the high proportion of homozygous patients with a low consanguinity rate found in this work and by Silva et al. (1999) in the same population.

The data obtained in this study confirm the high incidence of Type 1 GM1 gangliosidosis and the high frequency of two common mutations (R59H and 16221727 insG) in southern Brazil. It was, however, not possible to prove that the high frequency of the latter mutation is due to a founder effect.

\section{References}

Beattie RM and Harvey D (1992) Extensive and unusual Mongolian blue spots in a child with GM1 gangliosidosis type one. J Royal Soc Med 85:574-575.

Brunetti-Pierri N and Scaglia F (2008) GM gangliosidosis: Review of clinical, molecular, and therapeutic aspects. Mol Genet Metab 94:391-396.

Caciotti A, Donati MA, Boneh A, d'Azzo A, Federico A, Parini R, Antuzzi D, Bardelli T, Nosi D, Kimonis V, et al. (2005) Role of beta-galactosidase and elastin binding protein in lysosomal and nonlysosomal complexes of patients with GM1gangliosidosis. Hum Mutat 25:285-292.

Callahan JW (1999) Molecular basis of GM1 Gangliosidosis and Morquio disease type B. Structure-function studies of $\beta$-galactosidase and the nonlysosomal $\beta$-galactosidase-like protein. Biochim Biophys Acta 1445:85-103.

Giugliani R, Jackson M, Skinner SJR, Vimal CM, Fensom AH, Fahmy N, Sjövall A and Benson PF (1987) Progressive mental regression in siblings with Morquio's disease type B (MPS IV B). Clin Genet 32:313-325. 
Hilson WL, Okamura-Oho Y, Zhang S, Clarke JTR, Whelan DJ and Callahan JW (1995) Expression studies of two mutations in $\beta$-galactosidase that result in GM1 gangliosidosis. Am J Hum Genet 57:A180.

Lenicker HM, Agius PV, Young EP and Montalto SPA (1997) Infantile generalized GM1 gangliosidosis: High incidence in the Maltese Islands. J Inher Metab Dis 20:723-724.

Mayer FQ, Pereira FS, Fensom AH, Slade C, Matte U and Giugliani R (2009) New GLB1 mutation in siblings with Morquio type $\mathrm{B}$ disease presenting with mental regression. Mol Genet Metab 96:148.

Meikle P, Hopwood JJ, Clague AE and Carey WF (1999) Prevalence of lysosomal storage disorders. JAMA 281:249-254.

Miller SA, Dykes DD and Polesky HF (1988) A simple salting out procedure for extracting DNA from human nucleated cells. Nucleic Acids Res 16:1215.

Morreau H, Galjart NJ, Gillemans N, Willemsen R, van der Horst GT and d'Azzo A (1989) Alternative splicing of beta-galactosidase mRNA generates the classic lysosomal enzyme and a beta-galactosidase-related protein. J Biol Chem 264:20655-20663.

Morrone A, Bardelli T, Donati MA, Giorgi M, Di Rocco R, Gatti. R, Taddeucci G, Ricci R, d'Azzo A and Zammarchi E (1997) Identification of new mutations in six Italian patients affected by a variant form of infantile GM1 gangliosidosis with severe cardiomiopathy. Am J Hum Genet 61:A528.

Morrone A, Bardelli T, Donati MA, Giorgi M, Di Rocco M, Gatti R, Parini R, Ricci R, Taddeucci G, D'Azzo A, et al. (2000) $\beta$-galactosidase gene mutation affecting the lysosomal enzyme and the elastin-binding protein in GM1 gangliosidosis patients with cardiac involvement. Hum Mutat 15:354-366.

Orita M, Iwahana H, Kanazawa $H$, Hayashi $\mathrm{K}$ and Sekiya $\mathrm{T}$ (1989) Detection of polymorphism of human DNA by gel electrophoresis as single-strand conformation polymorphisms. Proc Natl Acad Sci USA 86:2766-2770.

Rozas J and Rozas R (2000) DnaSP v. 3.0: An integrated program for molecular population genetics and molecular evolution analysis. Bioinformatics 15:174-175.

Risch N, Tang H, Katzenstein H and Ekstein J (2003) Geographic distribution of disease mutations in the Ashkenazi Jewish population supports genetic drift over selection. Am J Hum Genet 72:812-822.

Santamaria R, Chabas A, Coll MJ, Miranda CS, Vilageliu L and Grinberg D (2006) Twenty-one novel mutations in the
GLB1 gene identified in a large group of GM1-gangliosidosis. Hum Mutat 27:1060.

Santamaria R, Blanco M, Chabas A, Grinberg D and Vilageliu L (2007a) Identification of 14 novel GLB1 mutations, including five deletions, in 19 patients with GM1 gangliosidosis from South America. Clin Genet 71: 273-279.

Santamaria R, Chabas A, Callahan JW, Grinberg D and Vilageliu L (2007b) Expression and characterization of 14 GLB1 mutant alleles found in GM1-gangliosidosis and Morquio B patients. J Lipid Res 48: 2275-2282.

Santana da Silva LC, Carvalho TS, da Silva FB, Morari L, Fachel AA, Pires R, Refosco LF, Desnick RJ, Giugliani R and Saraiva Pereira ML (2003) Molecular characterization of phenylketonuria in South Brazil. Mol Genet Metab 79:1724.

Severini MH, Silva CMD, Sopelsa A, Coelho J and Giugliani R (1999) High frequency of type 1 GM1 gangliosidosis in southern Brazil. Clin Genet 56:168-169.

Silva CMD, Severini MH, Sopelsa A, Coelho JC, Zaha A, d'Azzo A and Giugliani R (1999) Six novel $\beta$-galactosidase gene mutations in Brazilian patients with GM1-gangliosidosis. Hum Mutat 13:401-409.

Sinigerska I, Chandler D, Vaghjiani V, Hassanova I, Gooding R, Morrone A, Kremensky I and Kalaydjieva L (2006) Founder mutation causing infantile GM1-gangliosidosis in the Gypsy population. Mol Genet Metab 88:93-95.

Tamura K, Dudley J, Nei M and Kumar S (2007) MEGA4: Molecular Evolutionary Genetics Analysis (MEGA) software v. 4.0. Mol Biol Evol 24:1596-1599.

Takano T and Yamanouchi Y (1993) Assignment of human betagalactosidase-A gene to $3 \mathrm{p} 21.33$ by fluorescence in situ hybridization. Hum Genet 92:403-404.

Zhang S, Bagshaw R, Hilson W, Oho Y, Hinek A, Clarke JTR, Hinek A and Callahan JW (2000) Characterization of $\beta$-galactosidase mutations Asp332 $\rightarrow$ Asn and Arg148 $\rightarrow$ Ser, and a polymorphism, Ser532 $\rightarrow$ Gly, in a case of GM1 gangliosidosis. Biochem J 348:621-632.

Associate Editor: Paulo A. Otto

License information: This is an open-access article distributed under the terms of the Creative Commons Attribution License, which permits unrestricted use, distribution, and reproduction in any medium, provided the original work is properly cited. 